\title{
Toward Effective Immunotherapy for the Treatment of Malignant Brain Tumors
}

\author{
Duane A. Mitchell*† and John H. Sampson*** \\ ${ }^{*}$ Duke Brain Tumor Immunotherapy Program, Division of Neurosurgery, Department of Surgery; ${ }^{\dagger}$ Department of Pathology, \\ ${ }^{\ddagger}$ The Preston Robert Tisch Brain Tumor Center at Duke, Duke University Medical Center, Durham, North Carolina 27710
}

Summary: The immunologic treatment of cancer has long been heralded as a targeted molecular therapeutic with the promise of eradicating tumor cells with minimal damage to surrounding normal tissues. However, a demonstrative example of the efficacy of immunotherapy in modulating cancer progression is still lacking for most human cancers. Recent breakthroughs in our understanding of the mechanisms leading to full T-cell activation, and recognition of the importance of overcoming tumor-induced immunosuppressive mechanisms, have shed new light on how to generate effective anti-tumor immune responses in humans, and sparked a renewed and enthusiastic effort to realize the full potential of cancer immunotherapy. The immunologic treatment of invasive malignant brain tumors has not escaped this re-invigorated endeavor, and promising therapies are currently under active investigation in dozens of clinical trials at several institutions worldwide. This review will focus on some of the most important breakthroughs in our understanding of how to generate potent anti-tumor immune responses, and some of the clear challenges that lie ahead in achieving effective immunotherapy for the majority of patients with malignant brain tumors. A review of immunotherapeutic strategies currently under clinical evaluation, as well as an outline of promising novel approaches on the horizon, is included to provide perspective on the active and stalwart progress toward effective immunotherapy for the treatment of malignant brain tumors. Key Words: Glioma, immunotherapy, brain tumor, cancer vaccines, dendritic cells.
Despite aggressive, image-guided tumor resection, ${ }^{1}$ high-dose external beam radiotherapy or brachytherapy, and advances in efficacious adjuvant chemotherapy, patients with glioblastoma (GBM), which is the most common and deadly malignant brain tumor, still have a median survival of less than 15 months. ${ }^{2,3}$ The estimated cost of treatment for each patient with a malignant brain tumor is between $\$ 30,000$ and several hundred thousand dollars annually. Thus, the annual treatment cost alone for these patients, not accounting for the lost earning potential of affected individuals, is greater than the entire annual budget of the National Institute of Neurological Disorders and Stroke.

In evaluation of the quality-adjusted life-year saved, conventional therapy for patients with malignant brain tumors is the most expensive medical therapy currently provided in the United States. ${ }^{4}$ Furthermore, patients

Address correspondence and reprint requests to: Duane A. Mitchell, M.D., Ph.D., Duke University Medical Center, Division of Neurosurgery, Department of Surgery, DUMC Box 3050, Durham, NC 27710. E-mail: d.mitchell@duke.edu. treated with the aggressive multi-modality treatments that are used in the standard of care management of this disease are often left with incapacitating damage to surrounding normal brain and systemic tissues. ${ }^{5,6}$ Thus, to be more effective, therapeutic strategies for malignant brain tumors will have to precisely target residual invasive tumor cells while minimizing collateral damage to the neighboring eloquent brain. The rationale for using the immune system to target brain tumors is based on the premise that the inherent biologic specificity of the immune system could meet the clear and urgent need for more precise medical therapy.

\section{CANCER IMMUNOTHERAPY: A PERSONALIZED MEDICINE PARADIGM}

The immune system is an intricate network of innumerable cellular and molecular mediators that are so exquisitely interconnected and refined that it is capable of recognizing a foreign pathogen within minutes of breaching the outer barriers of the human body, and responding with a myriad of innate defense mechanisms 
and an array of specific humoral and cellular effectors that can control a rapidly expanding and invasive infection and eliminate almost every infected cell from the body. For more than a century now, tumor immunologists have sought to leverage this amazing cytotoxic power and exquisite specificity against malignant cancer cells that spread throughout afflicted hosts with as dire consequences as an uncontrolled microbial infection.

Current efforts in oncology treatment development are directed at the discovery of "targeted therapeutics" that attack specific pathways operative in cancer cells and are key to the maintenance of malignant phenotype. Delineating the phenotype and genotype of tumor cells using the variety of available "omic" technologies, such as genomics and proteonomics to match them most appropriately to treatments known to be effective against cancers that share a genetic or proteomic "profile" constitutes a major current effort to increase the efficacy of oncology treatment regimens through proper patient selection. This quest in drug discovery for more specific and targeted cellular pathway inhibitors, coupled with the molecular interrogation of tumor specimens to match the most effective available pharmacologic treatments, is often descriptive of the era of "personalized medicine" that we are diligently working toward. ${ }^{7}$

In many ways, although the tumor immunologists can probably not be credited with coining the phrase of personalized medicine, they very well may be credited with the first attempts to realize such personalized medical treatments for patients with malignancy. Effective cancer immunotherapy captures all of the essential ingredients of a targeted therapeutic that is uniquely matched to the antigenic profile of a given tumor, and is specifically designed to leverage its effects against tumor cells expressing a unique antigenic profile, while limiting "off target" effects on normal cells that do not share expression of these antigens. The inherent premise of immunotherapy does not base treatment strategy on a shared histopathologic appearance and natural disease history as conventional treatment paradigms, but rather bases therapeutic susceptibility almost entirely on the molecular antigenic profile of the tumor, and whether the tumor does or does not express an antigen (biomarker) that can be effectively targeted by the immune system. A cancer vaccine developed against an antigenic target such as epidermal growth factor receptor variant 3 (EGFRvIII), for example, would be expected to be effective only against tumor cells expressing this molecular target. Thus patients with the same pathologic diagnosis of malignant glioma selected upfront as EGFRvIII vaccine candidates based on expression of this biomarker was inherent in its initial clinical evaluation. Cancer immunotherapy may have the added advantage over other cytotoxic or cytostatic mechanisms, in that the immune system kills targeted cells based on the effective activa- tion and recognition of a particular antigen(s) within the target cell, but is not dependent on that target playing a key role in the oncogenic phenotype for executing cytolytic-killing mechanisms. Thus the validation of potential targets for tumor immunotherapy is simplified to expression analysis in normal and malignant tissues and the immunogenicity of the target itself. This is not to suggest that resistance mechanisms to immunologic killing within tumor cells do not exist nor are insignificant, but candidates for immunotherapeutic attack can be evaluated based on their differential expression in tumor cells alone without necessitating a role in tumorigenesis.

Thus, the successful development of cancer immunotherapy has long been based on the now widely accepted concepts captivated under the brand name of "personalized medicine" include the following: 1) that efforts in oncology therapeutics be directed toward the development of treatments that exploit specific molecular differences between normal cells and tumor cells; 2) that treatments are driven by biomarkers that can differentiate susceptible tumor types from nonsusceptible ones sharing the same or distinct pathological diagnosis; 3) that treatments have limited off-target effects against normal tissues by exploiting biological targets operative only in tumor cells; and 4) that treatments ideally can be combined to address the inherent heterogeneity of genetic and epigenetic phenotypes that exist within most malignant cancers. Furthermore, the bioavailability of the immune system's humoral and cellular effector mechanisms have been shown to be system-wide, with even the once believed to be immunoprivileged CNS being effectively surveyed by host immune defenses. ${ }^{8}$

Active immunotherapy (the generation of effective host immunity against tumor-specific antigens) has been shown, at least in preclinical models, to posses an additional benefit that no other targeted therapeutic possesses, and that is the capacity to establish immunologic memory recall responses against immunized antigens that can provide long-term surveillance against tumor recurrence. $^{9,10}$

Suffice to say that with all of the apparent advantages that immunotherapy has to offer, the clinical realization of these advantages is still lacking in the treatment of most human cancers. Notable exceptions to this generalization have been the effective use of adoptive cellular therapy against cancers associated with viral infections, such as Epstein Barr virus (EBV)-associated lymphomas and donor leukocyte infusions against lymphoproliferative diseases and some hematologic malignancies in allogeneic transplant recipients. ${ }^{11,12}$ Recent advances in our understanding of the potent effects of tumor-induced immunosuppression and homeostatic regulatory mechanisms that govern lymphocyte expansion and function, however, have provided new insights into how to achieve and sustain potent immune responses in tumor bearing 
hosts. These advances have already begun to demonstrate remarkable clinical responses in patients with systemic tumors and hold significant promise for improving immunotherapy for patients with malignant brain tumors.

\section{CURRENT EFFORTS IN IMMUNOTHERAPY FOR MALIGNANT GLIOMAS}

\section{Tumor-specific rejection antigens and EGFRvIII}

Most well-characterized tumor antigens that have been identified represent over-expressed normal proteins. These self-proteins are likely limited in their capacity to generate potent immune responses to vaccination due to some degree of tolerance, and if effectively targeted would likely precipitate some degree of autoimmunity. ${ }^{13,14} \mathrm{Con}$ versely, tumor-specific antigens derived from tumor-associated mutations in somatic genes would not be as amenable to central tolerance. These mutations would also less likely be associated with autoimmunity if potent immune responses were to be generated against these targets due to absence in normal tissues. In fact, studies examining the immunologic recognition of tumor antigens in patients with malignancy have shown that the majority of the host immunologic response is directed against tumor-specific antigens and not the readily studied over-expressed self antigens and differentiation antigens that have been described in most tumor types. ${ }^{15}$ These antigenic mutations, however, arise sporadically during errors in cellular division and tumor expansion, ${ }^{16,17}$ and thus would be predicted to be patientspecific and not necessarily linked to the oncogenic process.

EGFRvIII, however, is a rare example of a frequent and consistent tumor-specific mutation, central to the neoplastic process, that consists of an in-frame deletion of 801 base pairs from the extracellular domain of the EGFR that splits a codon and produces a novel glycine at the fusion junction. ${ }^{18,19}$ This mutation encodes a continually active tyrosine kinase $\mathrm{e}^{20,21}$ that enhances tumorgenicity ${ }^{21-24}$ and migration, ${ }^{25,26}$ and confers radiation and chemotherapeutic resistance ${ }^{27-32}$ to tumor cells. The EGFRvIII mutation is most frequently seen in patients with $\mathrm{GBM},{ }^{33-39}$ but has been found in a broad array of other common cancers. ${ }^{33,38-45}$ The new glycine inserted at the fusion junction of normally distant parts of the extracellular domain results in a tumor-specific epitope not found in any normal adult tissues. ${ }^{46}$ The exquisite tumor-specificity of EGFRvIII; its clonal expression in GBMs and other common tumors; its absence in any normal tissues; and its importance in the oncogenic phenotype of tumors make EGFRvIII an ideal target for antitumor immunotherapy. ${ }^{41,42,46,47}$

We have demonstrated in clinical studies in both phases I and II that patients with newly-diagnosed GBM who received vaccinations targeting a peptide spanning the EGFRvIII mutated junction induce potent EGFRvIIIspecific immune responses and patient survival that significantly exceeds that of historical controls. ${ }^{48}$ The efficacy of these EGFRvIII peptide vaccines (CDX-110 [Celldex/Avant/Pfizer, Inc]) in patients with newly-diagnosed GBM is currently being evaluated in large-scale clinical trials to confirm these promising early clinical findings.

\section{Peptide vaccines}

Peptide vaccines are of significant interest in the field of immunotherapy due to their ease of manufacturing and administration, and the capacity to induce antigenspecific cellular and humoral responses. In addition to EGFRvIII, a growing list of candidate antigens in malignant brain tumors have been identified that could serve as substrates for peptide-based cancer vaccines. These included melanoma/testis antigens, ${ }^{49-53}$ viral antigens, ${ }^{54-58}$ cytokine receptors, ${ }^{59,60}$ and differentiation antigens expressed in malignant gliomas. ${ }^{61}$ Clinical trials evaluating peptide vaccines for malignant glioma have demonstrated capacity to induce tumor-specific immune responses in patients with primary and recurrent gliomas and elicit early signs of clinical responses that await confirmation in larger scale clinical trials. ${ }^{48,62-64}$ Several clinical trials evaluating specific antigenic peptides, peptide fractions eluted from tumor cell surfaces or extracts, and peptide-bound chaperone proteins, such as heatshock proteins, are currently underway to assess the potential efficacy of peptide-based vaccines for malignant brain tumors.

\section{Gene-modified tumor cell vaccines}

One immunotherapeutic strategy is to use entire malignant tumor cells modified to render them more immunogenic and incapable of forming new tumors as the basis for vaccine formulation. These gene-modified tumor vaccines are then inoculated in patients with the aim of inducing immune responses against the myriad of uncharacterized and patient-specific antigens present in transformed tumor cells. Fakhrai et al. ${ }^{65}$ used autologous tumor cells genetically modified with a transforming growth factor-beta2 (TGF- $\beta 2$ ) antisense vector to reverse the immunosuppressive effects of TGF- $\beta 2$ and elicit immunologic responses in patients with GBM. The investigators treated six patients with progressive GBM and reported objective clinical responses in two patients and disease stabilization in two patients, as well as the induction of tumor-specific immunity as measured by DTH testing and antibody titers.

Okada et al. ${ }^{66,67}$ have used autologous glioma cell vaccines secreting interleukin(IL)-4 or co-injected with IL-4 secreting fibroblasts in patients with recurrent GBM. These vaccines were without any adverse reactions other than local inflammation at the vaccine site (i.e, the thigh). The authors also report induction of sys- 
temic tumor-specific immunologic responses and radiographic responses in treated patients, highlighting the potential promise of this treatment, but they also cite the duration of time required for vaccine preparation (i.e., greater than 7 weeks) as a major limitation for usage in patients with recurrent glioma.

Several gene-modified tumor vaccines are under current clinical evaluation using autologous glioma cells modified to secrete a variety of cytokines such as IL-4, granulocyte/macrophage colony stimulating factor (GMCSF), or IL-12 that have shown promise in preclinical therapeutic models of malignant glioma.

\section{DENDRITIC CELL THERAPY}

Dendritic cells (DCs) are potent immunostimulatory cells that continuously sample the antigenic environment of the host and specifically activate CD4+ and CD8+ T-cells and B-cells. ${ }^{68,69}$ They are at the crossroads of many of the elegant networks of the immune system, and DCs may represent the most promising contemporary biologic entity for realizing the promise of immunotherapy. Potent immune responses and encouraging clinical results have been seen in phase I and II human clinical trials in systemic cancers, ${ }^{70-86}$ and numerous animal studies, including many of our own, ${ }^{9,10,87}$ have demonstrated potent antitumor responses using DC-based immunotherapy against CNS tumors. ${ }^{88,89}$

\section{VACCINES TARGETING TUMOR-SPECIFIC ANTIGENS}

We completed a phase I clinical trial in which 16 patients with malignant gliomas (i.e., 13 GBM, 3 World Health Organization grade III glioma) received intradermal (i.d.) immunizations with autologous DC pulsed with a keyhole limpet hemocyanin (KLH) conjugate of a peptide spanning the mutated region of EGFRvIII after completion of radiation therapy. ${ }^{90}$ The i.d. route of administration was supported by evidence that DC delivered in this manner will migrate to lymph nodes ${ }^{91,92}$ and subsequently present antigen to $\mathrm{T}$ lymphocytes, as well as by prior studies comparing the ability of various routes of administration to elicit strong T-cell-mediated immunity. ${ }^{93}$ The enrolled patient population consisted of adults with malignant gliomas who had undergone gross total tumor resection and radiotherapy. Patients underwent leukapheresis to remove autologous peripheral blood mononuclear cells (PBMC), which were cultured in GM-CSF and IL-4 to generate DC. The DCs were pulsed with peptide spanning of the mutated region of EGFRvIII/KLH and matured in a cocktail of tumor necrosis factor- $\alpha$, IL- $1 \beta$, and IL- 6 (but not prostaglandin E2 [PGE2], due to some concern over a counterproductive effect on DC IL-12 production ${ }^{94}$ ) before be- ing delivered back to the patient in 3 biweekly i.d. injections.

Immunized patients demonstrated induction of immunologic responses, which were not detectable prior to vaccination, without any evidence of adverse events other than grades I and II local reactions at the vaccination site. For patients with GBM $(\mathrm{n}=13)$, the median survival time was 110.8 weeks, which compares favorably with other published reports in similar patient populations using temozolomide ${ }^{95}$ or carmustine wafers, ${ }^{96}$ in which median survivals were 63.3 weeks and 59.6 weeks, respectively. These findings suggest that autologous mature DCs loaded with the tumor-specific antigen, peptide spanning the mutated region of EGFRvIII, are safe and may induce beneficial immunologic and clinical responses in patients with malignant gliomas.

\section{Tumor lysate or unfractionated peptide pulsed DC vaccines}

The first trial of DC vaccination in patients with malignant glioma was published by $\mathrm{Yu}$ et al. ${ }^{88}$ in 2001 . A demonstrable increase in tumor-specific cytotoxicity was successfully developed in four out of seven testable patients who received DC pulsed with major histocompatibility complex-I peptides eluted from the surface of autologous glioma cells. Furthermore, two out of four patients who underwent reoperation demonstrated robust $\mathrm{CD}^{+}$and memory $\left(\mathrm{CD} 45 \mathrm{RO}^{+}\right) \mathrm{T}$-cell infiltrates in areas of the tumor. Based on the small sample size, no reliable data on survival could be generated, but the treatment proved safe. ${ }^{88}$

Parajuli et al. ${ }^{97}$ have reported the results of an in vitro human DC study that examined the ability of different DC-based strategies to induce effective T-cell responses against malignant astrocytomas. DCs were generated from patient PBMC and were fused with autologous tumor cells or pulsed with total tumor RNA or tumor lysate. They were then assayed for their respective abilities to stimulate tumor-specific T-cell proliferation and cytotoxic $\mathrm{T}$ lymphocyte responses in vitro. No significant differences were found between the various DC arms in their T-cell stimulatory capacity; all showed enhanced cytotoxicity that was further augmented by addition of CD40 ligand during T-cell stimulation. ${ }^{98}$ The data should be helpful in designing protocols for DC-based immunotherapy of malignant astrocytomas.

Liau et al. ${ }^{99}$ reported the results of a phase I trial of DC pulsed with peptides that were acid-eluted from the surface of resected, autologous tumor, and were administered to 12 GBM patients in 3 bi-weekly i.d. injections. There were no adverse effects of treatment and evidence of increased immunologic responses against autologous tumor was observed in half of the treated patients. Promising prolongation of survival (median survival, 23.4 months) compared with historical controls was observed, 
and a multi-center randomized clinical trial was initiated for further confirmation of these results.

In the largest series of DC vaccinated patients published to date, De Vleeschouwer et al. ${ }^{100}$ reported the results of 56 patients (both pediatric and adult) with relapsed GBM who were given at least three vaccinations with autologous mature DCs loaded with autologous tumor lysates. The treatment was well tolerated with a single serious adverse event of vaccine-related edema in a patient with gross residual disease. The median progression-free survival and overall survival of the group was 3 months and 9.6 months respectively, with a 2 -year overall survival of $14.8 \%$. Patients were treated in three consecutive cohorts, with progressively shorter vaccination intervals per cohort. The investigators observed a trend toward improved progression-free survival with a shorter vaccination interval (4 weekly injections with boosts of intradermal injections of $1.5 \mathrm{mg}$ of autologous tumor lysate). The vaccination of patients with recurrent disease and likely significant tumor-induced immunosuppression may have contributed to the limited overall clinical responses, although the authors note a small but encouraging 2-year survival rate in some patients with recurrent disease.

Recently, Wheeler et al. ${ }^{101}$ reported a statistically significant correlation between vaccine-induced immune responses in patients with GBM receiving autologous tumor lysate pulsed DCs and times to tumor progression and survival. Responders were classified as patients with a greater than 1.5-fold enhancement of interferon- $\gamma$ production (measured by qPCR in total PBMCs stimulatated by autologous tumor-lysate pulsed DCs) relative to prevaccine levels and post-vaccine tumor progression survival was significantly longer in responders $(642 \pm 61$ days) than nonresponders $(430 \pm 50$ days $)$ when all patients were analyzed as a group (both recurrent and newly-diagnosed GBM) $(p=0.041)$. Separate analysis of patients with recurrent disease showed a similar trend toward increased survival in responders, but this did not reach statistical significance $(p=0.067)$. This phase II study using a single immunologic response marker (interferon- $\gamma$ ) suggests that the establishment of validated immunologic markers for treatment responsiveness to immunotherapy may be feasible in larger studies of immunotherapy in patients with malignant glioma.

\section{RNA-loaded DC vaccines}

Tumor material is often limited in patients with malignant brain tumors, and thus vaccine preparations dependent on obtaining sufficient tumor tissue may be limited in broad application to patients. The use of RNA to encode tumor antigens for DCs was pioneered by Drs. Nair and Gilboa, but the ability of RNA-loaded DCs to stimulate potent antitumor immunity has been independently confirmed in murine and human systems. ${ }^{102,103}$ In fact, there is accumulating evidence that RNA transfection represents a superior method for loading antigens onto DCs. ${ }^{104-106}$ This novel and innovative approach to DC-antigen loading has multiple conceptual advantages over other forms of antigen delivery as well. RNA-based antigen loading does not require knowledge of major histocompatibility complex restriction, and responses are not restricted to single major histocompatibility complex haplotypes or to a narrow B- or T-cell repertoire. This diversity increases the likelihood of inducing effective and sustained antitumor immune responses by simultaneous activation of both cytotoxic $\mathrm{T}$ lymphocytes and helper T-cells. ${ }^{107-109}$ Using molecular techniques, RNA can be amplified, and in vitro it can be transcribed from DNA templates from cloned tumor antigens or from RNA libraries isolated from as few as 100 tumor cells, thus providing a renewable source of tumor antigen for vaccine preparation. ${ }^{110}$ Furthermore, in direct comparisons, RNA-loaded DCs have been found to be better stimulators of antigen-specific T-cells than other approaches. ${ }^{105}$ Finally, RNA also carries a significant safety advantage, not possessed by other nucleic acid or viral vectors, in that it can not be integrated permanently into the host genome. However, the time required for generation of tumor-specific RNA, either isolated from tumor cells or in vitro transcribed from cloned cDNA templates, and the labile nature of RNA molecules are potential limitations to the use of RNA as a source of tumor antigens.

Caruso et al. ${ }^{111}$ used tumor RNA-pulsed DCs to vaccinate seven children with recurrent brain cancers (anaplastic astrocytoma $[\mathrm{n}=1]$, GBM [n = 2], ependymoma $[\mathrm{n}=2]$, pleomorphic xanthoastrocytoma $[\mathrm{n}=1]$, and ependymoma $[n=1])$ in a phase I clinical study. Induction of tumor-specific immune responses was observed in two patients, and clinical responses were observed in three patients as assessed by MRI (two disease stabilizations and one partial response).

Methods for loading DCs with RNA have been significantly improved since the publication of these trial results, as the investigators used simple co-incubation of DCs with "naked" tumor RNA for loading with tumor antigens. Electroporation of RNA into DC has proven to achieve much higher expression from antigen-encoding RNA and likely will significantly improve immunologic responses against RNA pulsed DCs in humans. ${ }^{112} \mathrm{We}$ are currently evaluating RNA-electroporated DC vaccines in the context of several clinical trials at our institution.

Although the use of antigen-pulsed DCs appears promising in early clinical trials for treatment of brain tumors, these cells have also been shown to be quite capable of initiating significant autoimmune responses in murine models, and there has been one incident of a spontaneous generalized vitiligo that occurred after intravenous infu- 
sion of DCs in a patient with melanoma. ${ }^{113}$ Although our group and others have demonstrated that DCs loaded with unselected tumor-derived antigens induce potent, specific, and clinically effective immune responses against brain tumors in rodent models without the induction of autoimmune reactivity, ${ }^{10,87,89,114}$ and although no autoimmune reactions have been identified in human DC trials in patients with malignant brain tumors ${ }^{88}$ immunization in preclinical studies has only been effective when given before tumor challenge or in the context of very small established tumors. These data suggest that for DC-based immunotherapy to be effective in the context of large human tumors, a very strong and sustained antitumor immune response will be required. ${ }^{115}$ In animal models, when such responses have been generated against tumor-associated antigens that are shared with host cells, severe and clinically significant autoimmune disease has occasionally resulted. ${ }^{16}$ Thus, as our capacity to engender more potent immunologic responses in humans continues to advance, careful and long-term toxicity evaluation will be necessary to ensure the safe and effective development of this promising modality.

\section{ADOPTIVE CELLULAR THERAPY}

Adoptive immunotherapy encompasses treatments that involve transfer of autologous lymphocytes that have been expanded ex vivo against tumor specific antigens. Treatment approaches have differed in the types of cells administered, the route of administration, and the activation status of the cells. Cell types that have been used in adoptive immunotherapy for malignant brain tumors include 1) PBMC; ${ }^{117,118}$ 2) lymphokine-activated killer cells; ${ }^{119-121} 3$ ) mitogen-activated killer cells; ${ }^{122,123}$ 4) tumor-infiltrating lymphocytes; ${ }^{124}$ and 5) antigen-specific and unselected cytotoxic T-cell lymphocytes. ${ }^{125,126}$ Routes of administration have generally been either systemic or into the tumor cavity (also known as. intralesional or loco-regional). Clinical studies evaluating these approaches have demonstrated the safety of these treatments in patients with malignant brain tumors and a minority of patients was observed to have achieved objective clinical response to treatment.

Recent advances using genetically engineered lymphocytes with redirected specificity for antigens expressed in malignant brain tumors provides an opportunity to generate large numbers of tumor-specific lymphocytes from easily accessible pools of peripheral blood lymphocytes and shows exciting potential as a novel treatment strategy. ${ }^{127}$ However, due to the complexity and labor intense nature of adoptive cellular therapy protocols, in general, this modality has lagged significantly behind effort in development of active vaccinations using DCs, tumor cells, or defined antigens delivered as peptides or through viral and nonviral expression vectors.
However, striking advances have recently been made in the success of treating advanced metastatic melanoma using nonmyeloablative and myeloablative chemotherapy conditioning regimens for lymphodepletion prior to adoptive T-cell transfer and exogenous IL-2 support. ${ }^{128,129}$ The mechanistic principles underlying these treatment advances have also been begun to be elucidated in experimental mouse models. ${ }^{130,131}$ Thus, adoptive cellular therapy after lymphodepletion has recently emerged as the most effective treatment strategy to date for advanced refractory melanoma with objective responses achieved in greater than $50 \%$ of treated patients. ${ }^{132}$ Leveraging the concepts elucidated in this treatment strategy toward effective immunotherapy against malignant brain tumors seems to be of paramount interest, especially given that complete regressions of metastatic lesions within the CNS have been observed in patients treated with this approach.

\section{EMERGING CONCEPTS IN IMMUNOTHERAPY FOR MALIGNANT BRAIN TUMORS}

\section{Lymphopenia and homeostatic proliferation}

After periods of lymphopenia, there is a homeostatic proliferation of the remaining lymphocytes of the host, which is designed to recover normal lymphocyte counts. ${ }^{133}$ Probably as a result of a surge in cytokines (IL-7, IL-15) in response to lymphopenia, lymphocytes undergoing homeostatic proliferation enjoy a reduced activation threshold ${ }^{133,134}$ and differentiate directly into effector memory T-cells capable of rapid and intense response to antigen. ${ }^{135}$ Still, lymphocytes must encounter their cognate antigen and compete for limiting amounts of these homeostatic cytokines to proliferate even under these conditions. ${ }^{133}$ Thus, B- or T-cells specific for antigens that predominate during this recovery period, such as those provided in the form of a vaccine or adoptively transferred after ex vivo expansion against specific antigens, have a competitive advantage and become disproportionately over-represented in the recovering lymphocyte population both in murine models ${ }^{136,137}$ and in humans. ${ }^{138}$ These skewed homeostatic responses have been shown to enhance antitumor immunity, ${ }^{136,137,139}$ but can also increase the risk of autoimmunity. ${ }^{140,141}$ Futhermore, lymphodepletion may remove inhibitory regulatory T-cells, further accentuating the effectiveness of antitumor immunotherapy. ${ }^{142,143}$

Leveraging this principle, Dudley et al. ${ }^{144}$ have used intentional nonmyeloablative lymphodepletion to enhance the preferential expansion and maintenance of adoptively transferred, tumor-specific T-cells. This has resulted in dramatic clinical responses, ${ }^{145-149}$ along with some autoimmune toxicity, in patients with advanced malignant melanoma. ${ }^{132,144}$ These studies have shown 
that under these conditions, transferred T-cells can expand dramatically in the lymphopenic host to constitute up to $90 \%$ of the T-cell repertoire of the host, and can be maintained for months after adoptive transfer. ${ }^{132,150}$ These studies demonstrated that clinical regression of systemic disease correlates with the frequency of tumorspecific T-cells achieved in the peripheral blood and persistence of these cells in vivo. ${ }^{145-149,151}$ At least in murine models, this antitumor effect was also significantly enhanced by autologous stem cell support. ${ }^{152}$

\section{Immunosuppression in GBM and IL-2R $\alpha^{+}$ regulatory $\mathrm{T}$-cells}

A substantial barrier to the activation of antitumor immune responses in patients with GBM is their welldocumented impairment of T- and B-cell immunity. Although immunosuppressive factors secreted by the tumor clearly play a role, we have recently demonstrated that a major contributor to depressed cellular immunity in patients with GBM is an increased level of regulatory Tcells $\left(\mathrm{T}_{\text {Regs }}\right) .{ }^{153} \mathrm{~T}_{\text {Regs }}$ are a physiologic subset of $\mathrm{CD} 4^{+}$ $\mathrm{T}$-cells that normally comprise 5 to $10 \%$ of this compartment and serve to thwart pathological responses toward self antigens. They constitutively express high levels of the high-affinity IL-2R $\alpha$ (CD25) on their surface, ${ }^{154}$ and they can be identified even more specifically by expression of the intracellular transcription factor, FOXP3. $\mathrm{T}_{\text {Regs }}$ potently inhibit T-cell cytokine secretion and proliferation, ${ }^{155-159}$ directly curtail the generation and expansion of endogenous or induced immune responses, ${ }^{154,160-168}$ and appear to play a significant role in hindering immunity to normal and tumor-associated antigens. ${ }^{169,170}$ Accordingly, increased levels of $\mathrm{T}_{\text {Regs }}$ have been found in the tumors and peripheral blood of patients with various tumors including GBM. ${ }^{153,171-175}$ The relative importance and precise interactions between systemic and intratumoral $\mathrm{T}_{\text {Regs }}$ has not been established. ${ }^{176-178}$ Strategies to inhibit or deplete $\mathrm{T}_{\text {Regs }}$ including CD25 blockade using MAbs, CD25-binding immunotoxins, or pharmacologic inhibition of $\mathrm{T}_{\text {Reg }}$ activity are under current clinical and preclinical evaluation in our laboratory and others. ${ }^{179-181}$

\section{BEYOND PROOF-OF-CONCEPT AND TOWARD CLINICAL EFFICACY}

The debate as to whether human tumors express proteins capable of serving as tumor rejection antigens that pre-occupied much of the early decades of tumor immunology and immunotherapy research has now been settled. It is clear that the immune system can recognize and mount significant cellular and humoral responses against over-expressed self antigens, as well as novel tumorspecific antigens in human tumors, including malignant brain tumors. Also, it is well-accepted that the once believed to be "immunoprivileged," and therefore inaccessible CNS, is readily surveyed by activated effector cells of the immune system, although less extensively and perhaps with attenuated function compared with lymphocytes surveying tissues in the periphery.

Therefore, continued advancement of immunotherapeutic efforts in the treatment of malignant brain tumors will be dependent on a concerted effort to push past the now-established feasibility and safety demonstration of immunotherapeutic treatments, and even beyond basic immunologic monitoring efforts using nonstandardized and noncomparable immunologic assays. Future efforts will need to focus on methods to significantly enhance the magnitude of immune responses and proportion of responding patients against targeted glioma antigens. These responses will need to be evaluated using standardized immunologic assays that can be compared across clinical trials within a given institution and ideally among different institutions. Although a myriad of newer targets and interventional strategies will undoubtedly continue to spring forth, investigators will need to conquer the difficult, but essential, task of quickly and objectively evaluating what likely constitutes a significant advance in treatment strategy, and therefore justifies a change in direction versus continuing to forge forward with incremental improvements in existing treatment strategies against identified antigenic targets.

An effort in understanding the molecular differences between clinical and immunologic responders and nonresponders to immunotherapeutic interventions will be very helpful in guiding further improvements and also in patient selection, and innovative trial designs are needed to rapidly evaluate complex biological therapies in larger scale and more definitive clinical studies.

The current emphasis on targeted molecular therapies and use of biomarkers and tumor signatures to guide treatment selection is optimally suited to match the exquisite specificity and precise targeting capacity of immunologic treatment regimens. Therefore, in our opinion, cancer immunotherapy represents a contemporary treatment modality whose time has finally come for a comprehensive and forward-looking clinical evaluation and rational investigational plan for the successful integration into the mainstay of effective therapies for treatment of malignant brain tumors.

\section{REFERENCES}

1. Kelly PJ. Stereotactic resection and its limitations in glial neoplasms. Stereotact Funct Neurosurg 1992;59:84-91.

2. Stupp R, Mason WP, van den Bent MJ, et al. Radiotherapy plus concomitant and adjuvant temozolomide for glioblastoma. N Engl J Med 2005;352:987-996.

3. Walker MD, Green SB, Byar DP, et al. Randomized comparisons of radiotherapy and nitrosoureas for the treatment of malignant glioma after surgery. N Engl J Med 1980;303:1323-1329.

4. Pickard JD, Bailey S, Sanderson H, Rees M, Garfield JS. Steps 
towards cost-benefit analysis of regional neurosurgical care. Brit Med J 1990;301:629-635.

5. Imperato JP, Paleologos NA, Vick NA. Effects of treatment on long-term survivors with malignant astrocytomas. Ann Neurol 1990;28:818-822.

6. Hall WA, Fodstad O. Immunotoxins and central nervous system neoplasia. J Neurosurg 1992;76:1-12.

7. Shai RM, Reichardt JK, Chen TC. Pharmacogenomics of brain cancer and personalized medicine in malignant gliomas. Future Oncol 2008;4:525-534.

8. Owens T, Renno T, Taupin V, Krakowski M. Inflammatory cytokines in the brain: does the CNS shape immune responses? Immunol Today 1994;15:566-571.

9. Heimberger AB, Archer GE, Crotty LE, et al. Dendritic cells pulsed with a tumor-specific peptide induce long-lasting immunity and are effective against murine intracerebral melanoma. Neurosurgery 2002;50:158-164.

10. Heimberger AB, Crotty LE, Archer GE, et al. Bone marrowderived dendritic cells pulsed with tumor homogenate induce immunity against syngeneic intracerebral glioma. J Neuroimmunol 2000;103:16-25.

11. Porter DL, Antin JH. Donor leukocyte infusions in myeloid malignancies: new strategies. Best Pract Res Clin Haematol 2006; 19:737-755.

12. Loren AW, Porter DL. Donor leukocyte infusions after unrelated donor hematopoietic stem cell transplantation. Curr Opin Oncol 2006;18:107-114.

13. Gilboa E. The promise of cancer vaccines. Nat Rev Canc 2004; 4:401-411.

14. Gilboa E. The makings of a tumor rejection antigen. Immunity 1999;11:263-270.

15. Lennerz V, Fatho M, Gentilini C, et al. The response of autologous $\mathrm{T}$ cells to a human melanoma is dominated by mutated neoantigens. Proc Natl Acad Sci U S A 2005;102:16013-16018.

16. Lengauer C, Kinzler KW, Vogelstein B. Genetic instabilities in human cancers. Nature 1998;396:643-649.

17. Loeb LA. A mutator phenotype in cancer. Cancer Res 2001;61: 3230-3239.

18. Bigner SH, Humphrey PA, Wong AJ, et al. Characterization of the epidermal growth factor receptor in human glioma cell lines and xenografts. Cancer Res 1990;50:8017-8022.

19. Libermann TA, Nusbaum HR, Razon N, et al. Amplification, enhanced expression and possible rearrangement of EGF receptor gene in primary human brain tumours of glial origin. Nature 1985;313:144-147.

20. Chu CT, Everiss KD, Wikstrand CJ, Batra SK, Kung HJ, Bigner DD. Receptor dimerization is not a factor in the signalling activity of a transforming variant epidermal growth factor receptor (EGFRvIII). Biochem J 1997;324:855-861.

21. Batra SK, Castelino-Prabhu S, Wikstrand CJ, et al. Epidermal growth factor ligand-independent, unregulated, cell-transforming potential of a naturally occurring human mutant EGFRvIII gene. Cell Growth Differ 1995;6:1251-1259.

22. Nishikawa R, Ji XD, Harmon RC, Lazar CS, Gill GN, Cavenee WK, et al. A mutant epidermal growth factor receptor common in human glioma confers enhanced tumorigenicity. Proc Natl Acad Sci U S A 1994;91:7727-7731.

23. Huang HS, Nagane M, Klingbeil CK, et al. The enhanced tumorigenic activity of a mutant epidermal growth factor receptor common in human cancers is mediated by threshold levels of constitutive tyrosine phosphorylation and unattenuated signaling. J Biol Chem 1997;272:2927-2935.

24. Moscatello DK, Montgomery RB, Sundareshan P, McDanel H, Wong MY, Wong AJ. Transformation and altered signal transduction by a naturally occurring mutant EGF receptor. Oncogene 1996;13:85-96.

25. Pedersen MW, Tkach V, Pedersen N, Berezin V, Poulsen HS. Expression of a naturally occurring constitutively active variant of the epidermal growth factor receptor in mouse fibroblasts increases motility. Int J Cancer 2004;108:643-653.

26. Boockvar JA, Kapitonov D, Kapoor G, et al. Constitutive EGFR signaling confers a motile phenotype to neural stem cells. Mol Cell Neurosci 2003;24:1116-1130.
27. Lammering G, Hewit TH, Holmes M, et al. Inhibition of the type III epidermal growth factor receptor variant mutant receptor by dominant-negative EGFR-CD533 enhances malignant glioma cell radiosensitivity. Clin Canc Res 2004;10:6732-6743.

28. Nagane M, Coufal F, Lin H, et al. A common mutant epidermal growth factor receptor confers enhanced tumorigenicity on human glioblastoma cells by increasing proliferation and reducing apoptosis. Cancer Res 1996;56:5079-5086.

29. Montgomery RB, Guzman J, O'Rourke DM, Stahl WL. Expression of oncogenic epidermal growth factor receptor family kinases induces paclitaxel resistance and alters beta-tubulin isotype expression. J Biol Chem 2000;275:17358-17363.

30. Lammering G, Valerie K, Lin P-S, Hewit TH, Schmidt-Ullrich RK. Radiation-induced activation of a common variant of EGFR confers enhanced radioresistance. Radiother Oncol 2004;72:267273.

31. Li B, Yuan M, Kim I-A, Chang C-M, Bernhard EJ, Shu H-KG. Mutant epidermal growth factor receptor displays increased signaling through the phosphatidylinositol-3 kinase/AKT pathway and promotes radioresistance in cells of astrocytic origin. Oncogene 2004;23:4594-4602.

32. Lammering G, Hewit TH, Valerie K, et al. EGFRvIII-mediated radioresistance through a strong cytoprotective response. Oncogene $2003 ; 22: 5545-5553$.

33. Wikstrand CJ, Hale LP, Batra SK, et al. Monoclonal antibodies against EGFRvIII are tumor specific and react with breast and lung carcinomas and malignant gliomas. Cancer Res 1995;55: 3140-3148.

34. Frederick L, Wang XY, Eley G, James CD. Diversity and frequency of epidermal growth factor receptor mutations in human glioblastomas. Cancer Res 2000;60:1383-1387.

35. Wong AJ, Ruppert JM, Bigner SH, et al. Structural alterations of the epidermal growth factor receptor gene in human gliomas. Proc Natl Acad Sci U S A 1992;89:2965-2969.

36. Sugawa N, Ekstrand AJ, James CD, Collins VP. Identical splicing of aberrant epidermal growth factor receptor transcripts from amplified rearranged genes in human glioblastomas. Proc Natl Acad Sci U S A 1990;87:8602-8606.

37. Ekstrand AJ, James CD, Cavenee WK, et al. Genes for epidermal growth factor receptor, transforming growth factor alpha, and epidermal growth factor and their expression in human gliomas in vivo. Cancer Res 1991;51:2164-2172.

38. Aldape KD, Ballman K, Furth A, et al. Immunohistochemical detection of EGFRvIII in high malignancy grade astrocytomas and evaluation of prognostic significance. J Neuropathol Exp Neurol 2004;63:700-707.

39. Heimberger AB, Hlatky R, Suki D, et al. Prognostic effect of epidermal growth factor receptor and EGFRvIII in glioblastoma multiforme patients. Clin Canc Res 2005;11:1462-1466.

40. Cunningham MP, Essapen S, Thomas H, Green M, Lovell DP, Topham C, et al. Coexpression, prognostic significance and predictive value of EGFR, EGFRvIII and phosphorylated EGFR in colorectal cancer. Int J Oncol 2005;27:317-325.

41. Garcia de Palazzo IE, Adams GP, Sundareshan P, et al. Expression of mutated epidermal growth factor receptor by non- small cell lung carcinomas. Cancer Res 1993;53:3217-3220.

42. Moscatello DK, Holgado-Madruga M, Godwin AK, et al. Frequent expression of a mutant epidermal growth factor receptor in multiple human tumors. Cancer Res 1995;55:5536-5539.

43. Luo X, Gong X, Tang CK. Suppression of EGFRvIII-mediated proliferation and tumorigenesis of breast cancer cells by ribozyme. Int J Cancer 2003;104:716-721.

44. Ge H, Gong X, Tang CK. Evidence of high incidence of EGFRvIII expression and coexpression with EGFR in human invasive breast cancer by laser capture microdissection and immunohistochemical analysis. Int J Cancer 2002;98:357-361.

45. Olapade-Olaopa EO, Moscatello DK, MacKay EH, et al. Evidence for the differential expression of a variant EGF receptor protein in human prostate cancer. Br J Canc 2000;82:186-194.

46. Humphrey PA, Wong AJ, Vogelstein B, et al. Anti-synthetic peptide antibody reacting at the fusion junction of deletion-mutant epidermal growth factor receptors in human glioblastoma. Proc Natl Acad Sci U S A 1990;87:4207-4211. 
47. Wikstrand CJ, Hale LP, Batra SK, et al. Monoclonal antibodies against EGFRvIII are tumor specific and react with breast and lung carcinomas and malignant gliomas. Cancer Res 1995;55: $3140-3148$.

48. Sampson JH, Archer GE, Mitchell DA, Heimberger AB, Bigner DD. Tumor-specific immunotherapy targeting the EGFRvIII mutation in patients with malignant glioma. Semin Immunol 2008; 20:267-275

49. Liao SK, Clarke BJ, Kwong PC, Brickenden A, Gallic BL, Dent PB. Common neuroectodermal antigens on human melanoma, neuroblastoma, retinoblastoma, glioblastoma and fetal brain revealed by hybridoma antibodies raised against melanoma cells. Eur J Immunol 1981;11:450-454.

50. Rimoldi D, Romero P, Carrel S. The human melanoma antigenencoding gene, MAGE-1, is expressed by other tumour cells of neuroectodermal origin such as glioblastomas and neuroblastomas. Int J Cancer 1993;54:527-528.

51. Sasaki M, Nakahira K, Kawano Y, et al. MAGE-E1, a new member of the melanoma-associated antigen gene family and its expression in human glioma. Cancer Res 2001;61:4809-4814.

52. Zhang JG, Eguchi J, Kruse CA, et al. Antigenic profiling of glioma cells to generate allogeneic vaccines or dendritic cellbased therapeutics. Clin Cancer Res 2007;13:566-575.

53. Zimmer C, Gottschalk J, Goebel S, Cervos-Navarro J. Melanomaassociated antigens in tumours of the nervous system: an immunohistochemical study with the monoclonal antibody HMB-45. Virchows Arch A Pathol Anat Histopathol 1992;420:121-126.

54. Cobbs CS, Harkins L, Samanta M, et al. Human cytomegalovirus infection and expression in human malignant glioma. Cancer Res 2002;62:3347-3350.

55. Mitchell DA, Xie W, Schmittling R, et al. Sensitive detection of human cytomegalovirus in tumors and peripheral blood of patients diagnosed with glioblastoma. Neuro Oncol 2008;10:10-18.

56. Scheurer ME, Bondy ML, Aldape KD, Albrecht T, El-Zein R. Detection of human cytomegalovirus in different histological types of gliomas. Acta Neuropathol 2008;116:79-86.

57. Soderberg-Naucler C. HCMV microinfections in inflammatory diseases and cancer. J Clin Virol 2008;41:218-223.

58. Prins RM, Cloughesy TF, Liau LM. Cytomegalovirus immunity after vaccination with autologous glioblastoma lysate. N Engl J Med 2008;359:539-541.

59. Mintz A, Debinski W. Cancer genetics/epigenetics and the $X$ chromosome: possible new links for malignant glioma pathogenesis and immune-based therapies. Crit Rev Oncog 2000;11: 77-95.

60. Debinski W. An immune regulatory cytokine receptor and glioblastoma multiforme: an unexpected link. Crit Rev Oncog 1998; 9:255-268.

61. Skog J. Glioma-specific antigens for immune tumor therapy. Expert Rev Vaccines 2006;5:793-802.

62. Schmittling RJ, Archer GE, Mitchell DA, et al. Detection of humoral response in patients with glioblastoma receiving EGFRvIII-KLH vaccines. J Immunol Methods 2008;339:74-81.

63. Izumoto S, Tsuboi A, Oka Y, et al. Phase II clinical trial of Wilms tumor 1 peptide vaccination for patients with recurrent glioblastoma multiforme. J Neurosurg 2008;108:963-971.

64. Yajima N, Yamanaka R, Mine T, et al. Immunologic evaluation of personalized peptide vaccination for patients with advanced malignant glioma. Clin Cancer Res 2005;11:5900-5911.

65. Fakhrai H, Mantil JC, Liu L, et al. Phase I clinical trial of a TGF-beta antisense-modified tumor cell vaccine in patients with advanced glioma. Cancer Gene Ther 2006;13:1052-1060.

66. Okada H, Lieberman FS, Walter KA, et al. Autologous glioma cell vaccine admixed with interleukin- 4 gene transfected fibroblasts in the treatment of patients with malignant gliomas. J Transl Med 2007;5:67.

67. Okada H, Pollack IF, Lotze MT, et al. Gene therapy of malignant gliomas: a phase I study of IL-4-HSV-TK gene-modified autologous tumor to elicit an immune response. Hum Gene Ther 2000;11:637-653.

68. Banchereau J, Steinman RM. Dendritic cells and the control of immunity. Nature 1998;392:245-252.
69. Steinman RM. Dendritic cells and the control of immunity: enhancing the efficiency of antigen presentation. Mt Sinai J Med 2001;68:106-166.

70. Fujii S, Shimizu K, Fujimoto K, et al. Analysis of a chronic myelogenous leukemia patient vaccinated with leukemic dendritic cells following autologous peripheral blood stem cell transplantation. Jpn J Cancer Res 1999;90:1117-1129.

71. Heiser A, Coleman D, Dannull J, et al. Autologous dendritic cells transfected with prostate-specific antigen RNA stimulate CTL responses against metastatic prostate tumors. J Clin Invest 2002; 109:409-417.

72. Su Z, Dannull J, Heiser A, et al. Immunological and clinical responses in metastatic renal cancer patients vaccinated with tumor RNA-transfected dendritic cells. Cancer Res 2003;63:21272133.

73. Holtl L, Rieser C, Papesh C, et al. Cellular and humoral immune responses in patients with metastatic renal cell carcinoma after vaccination with antigen pulsed dendritic cells. J Urol 1999;161: 777-782.

74. Lodge PA, Jones LA, Bader RA, Murphy GP, Salgaller ML. Dendritic cell-based immunotherapy of prostate cancer: immune monitoring of a phase II clinical trial. Cancer Res 2000;60:829 833.

75. Lim SH, Bailey-Wood R. Idiotypic protein-pulsed dendritic cell vaccination in multiple myeloma. Int J Cancer 1999;83:215-222.

76. Hsu FJ, Benike C, Fagnoni F, et al. Vaccination of patients with B-cell lympoma using autologous antigen-pulsed dendritic cells. Nat Med 1996;2:52-58.

77. Murphy GP, Tjoa BA, Simmons SJ, Rogers MK, Kenny GM, Jarisch J. Higher-dose and less frequent dendritic cell infusions with PSMA peptides in hormone-refractory metastatic prostate cancer patients. Prostate 2000;43:59-62.

78. Morse MA, Deng Y, Coleman D, et al. A Phase I study of active immunotherapy with carcinoembryonic antigen peptide (CAP-1)pulsed, autologous human cultured dendritic cells in patients with metastatic malignancies expressing carcinoembryonic antigen. Clin Cancer Res 1999;5:1331-1338.

79. Tjoa BA, Simmons SJ, Bowes VA, et al. Evaluation of phase I/II clinical trials in prostate cancer with dendritic cells and PSMA peptides. Prostate 1998;36:39-44.

80. Thurner B, Haendle I, Roder C, et al. Vaccination with mage-3A1 peptide-pulsed mature, monocyte-derived dendritic cells expands specific cytotoxic $\mathrm{T}$ cells and induces regression of some metastases in advanced stage IV melanoma. J Exp Med 1999;190: $1669-1678$.

81. Schuler-Thurner B, Dieckmann D, Keikavoussi P, et al. Mage-3 and influenza-matrix peptide-specific cytotoxic $\mathrm{T}$ cells are inducible in terminal stage HLA-A2.1 + melanoma patients by mature monocyte-derived dendritic cells. J Immunol 2000;165:34923496.

82. Salgaller ML, Tjoa BA, Lodge PA, et al. Dendritic cell-based immunotherapy of prostate cancer. Crit Rev Immunol 1998;18: 109-119.

83. Salgaller ML, Lodge PA, McLean JG, et al. Report of immune monitoring of prostate cancer patients undergoing T-cell therapy using dendritic cells pulsed with HLA-A2-specific peptides from prostate-specific membrane antigen (PSMA). Prostate 1998;35: $144-151$.

84. Rieser C, Ramoner R, Holtl L, et al. Mature dendritic cells induce T-helper type-1-dominant immune responses in patients with metastatic renal cell carcinoma. Urologia Internationalis 2000;63: 151-159.

85. Nestle FO, Alijagic S, Gilliet M, et al. Vaccination of melanoma patients with peptide- or tumor lysate-pulsed dendritic cells. Nat Med 1998;4:328-332.

86. Murphy G, Tjoa B, Ragde H, Kenny G, Boynton A. Phase I clinical trial: T-cell therapy for prostate cancer using autologous dendritic cells pulsed with HLA-A0201-specific peptides from prostate-specific membrane antigen. Prostate 1996;29:371-380.

87. Ashley DM, Faiola B, Nair S, Hale LP, Bigner DD, Gilboa E. Bone marrow-generated dendritic cells pulsed with tumor extracts or tumor RNA induce antitumor immunity against central nervous system tumors. J Exp Med 1997;186:1177-1182. 
88. Yu JS, Wheeler CJ, Zeltzer PM, et al. Vaccination of malignant glioma patients with peptide-pulsed dendritic cells elicits systemic cytotoxicity and intracranial T-cell infiltration. Cancer Res 2001;61:842-847.

89. Liau L, Black KL, Prins RM, et al. Treatment of intracranial gliomas with bone marrow-derived dendritic cells pulsed with tumor antigens. J Neurosurg 1999;90:1115-1124.

90. Sampson JH, Archer GE, Mitchell DA, Heimberger AB, Bigner DD. Tumor-specific immunotherapy targeting the EGFRvIII mutation in patients with malignant glioma. Semin Immunol 2008.

91. Morse MA, Coleman RE, Akabani G, Niehaus N, Coleman D, Lyerly HK. Migration of human dendritic cells after injection in patients with metastatic malignancies. Cancer Res 1999;59: $56-58$.

92. Barratt-Boyes SM, Zimmer MI, Harshyne LA, et al. Maturation and trafficking of monocyte-derived dendritic cells in monkeys: implications for dendritic cell-based vaccines. J Immunol 2000; 164:2487-2495.

93. Fong L, Brockstedt D, Benike C, Wu L, Engleman EG. Dendritic cells injected via different routes induce immunity in cancer patients. J Immunol 2001;166:4254-4259.

94. Kalinski P, Vieira PL, Schuitemaker JH, de Jong EC, Kapsenberg ML. Prostaglandin E(2) is a selective inducer of interleukin-12 p40 (IL-12p40) production and an inhibitor of bioactive IL-12p70 heterodimer. Blood 2001;97:3466-3469.

95. Stupp R, Mason WP, van den Bent MJ, et al. Radiotherapy plus Concomitant and Adjuvant Temozolomide for Glioblastoma. N Engl J Med 2005;352:987-996.

96. Westphal M, Hilt DC, Bortey E, et al. A phase 3 trial of local chemotherapy with biodegradable carmustine (BCNU) wafers (Gliadel wafers) in patients with primary malignant glioma. Neuro-oncology 2003;5:79-88.

97. Parajuli P, Mathupala S, Sloan AE. Systematic comparison of dendritic cell-based immunotherapeutic strategies for malignant gliomas: in vitro induction of cytolytic and natural killer-like T cells. Neurosurgery 2004;55:1194-1204.

98. Sloan AE, Parajuli P, Mathupala S. DC-tumor cell fusion for induction of tumor-specific T-cell response against malignant brain tumors: Comparison with DC pulsed with total tumor RNA or tumor lysate. In: Proceedings of the American Association for Cancer Research; 2002; San Francisco, CA, 2002.

99. Liau LM, Prins RM, Kiertscher SM, et al. Dendritic cell vaccination in glioblastoma patients induces systemic and intracranial T-cell responses modulated by the local central nervous system tumor microenvironment. Clin Cancer Res 2005;11:5515-5525.

100. De Vleeschouwer S, Fieuws S, Rutkowski S, et al. Postoperative adjuvant dendritic cell-based immunotherapy in patients with relapsed glioblastoma multiforme. Clin Cancer Res 2008;14:30983104.

101. Wheeler CJ, Black KL, Liu G, et al. Vaccination elicits correlated immune and clinical responses in glioblastoma multiforme patients. Cancer Res 2008;68:5955-5964.

102. Morse MA, Nair SK, Mosca PJ, et al. Immunotherapy with autologous, human dendritic cells transfected with carcinoembryonic antigen mRNA. Cancer Invest 2003;21:341-349.

103. Boczkowski D, Nair SK, Snyder D, Gilboa E. Dendritic cells pulsed with RNA are potent antigen-presenting cells in vitro and in vivo. J Exp Med 1996;184:465-472.

104. Van Tendeloo VF, Ponsaerts P, Lardon F, et al. Highly efficient gene delivery by mRNA electroporation in human hematopoietic cells: superiority to lipofection and passive pulsing of mRNA and to electroporation of plasmid cDNA for tumor antigen loading of dendritic cells. Blood 2001;98:49-56.

105. Strobel I, Berchtold S, Gotze A, Schulze U, Schuler G, Steinkasserer A. Human dendritic cells transfected with either RNA or DNA encoding influenza matrix protein M1 differ in their ability to stimulate cytotoxic T lymphocytes. Gene Ther 2000;7:2028-2035.

106. Mitchell DA, Nair SK. RNA-transfected dendritic cells in cancer immunotherapy. J Clin Invest 2000;106:1065-1069.

107. Kim JJ, Trivedi NN, Wilson DM, Mahalingam S, et al. Molecular and immunological analysis of genetic prostate specific antigen (PSA) vaccine. Oncogene 1998;17:3125-3135.
108. Sercarz EE, Lehmann PV, Ametani A, Benichou G, Miller A, Moudgil K. Dominance and crypticity of T cell antigenic determinants. Ann Rev Immunol 1993;11:729-766.

109. Kundig TM, Bachmann MF, Oehen S, et al. On the role of antigen in maintaining cytotoxic T-cell memory. Proc Natl Acad Sci U S A 1996;93:9716-9723.

110. Boczkowski D, Nair SK, Nam JH, Lyerly HK, Gilboa E. Induction of tumor immunity and cytotoxic $\mathrm{T}$ lymphocyte responses using dendritic cells transfected with messenger RNA amplified from tumor cells. Cancer Res 2000;60:1028-1034.

111. Caruso DA, Orme LM, Neale AM, et al. Results of a phase 1 study utilizing monocyte-derived dendritic cells pulsed with tumor RNA in children and young adults with brain cancer. Neurooncol 2004;6:236-246.

112. Van Tendeloo VF, Ponsaerts P, Lardon F, et al. Highly efficient gene delivery by mRNA electroporation in human hematopoietic cells: superiority to lipofection and passive pulsing of mRNA and to electroporation of plasmid cDNA for tumor antigen loading of dendritic cells. Blood 2001;98:49-56.

113. Mackensen A, Herbst B, Chen JL, et al. Phase I study in melanoma patients of a vaccine with peptide-pulsed dendritic cells generated in vitro from $\mathrm{CD} 34(+)$ hematopoietic progenitor cells. Int J Cancer 2000;86:385-392.

114. Heimberger AB, Archer GE, Crotty LE, et al. Dendritic cells pulsed with a tumor-specific peptide induce long-lasting immunity and are effective against murine intracerebral melanoma. Neurosurgery 2002;50:158-166.

115. Ochsenbein AF, Klenerman P, Karrer U, et al. Immune surveillance against a solid tumor fails because of immunological ignorance. Proc Natl Acad Sci U S A 1999;96:2233-2238.

116. Ludewig B, Ochsenbein AF, Odermatt B, Paulin D, Hengartner $\mathrm{H}$, Zinkernagel RM. Immunotherapy with dendritic cells directed against tumor antigens shared with normal host cells results in severe autoimmune disease. J Exp Med 2000;191:795-804.

117. Steinbok P, Thomas JP, Grossman L, Dolman CL. Intratumoral autologous mononuclear cells in the treatment of recurrent glioblastoma multiforme. A phase 1 (toxicity) study. J Neurooncol 1984;2:147-151.

118. Young H, Kaplan A, Regelson W. Immunotherapy with autologous white cell infusions ("lymphocytes") in the treatment of recurrrent glioblastoma multiforme: a preliminary report. Cancer 1977;40:1037-1044.

119. Hayes RL, Koslow M, Hiesiger EM, et al. Improved long term survival after intracavitary interleukin-2 and lymphokine-activated killer cells for adults with recurrent malignant glioma. Cancer 1995; 76:840-852.

120. Blancher A, Roubinet F, Grancher AS, et al. Local immunotherapy of recurrent glioblastoma multiforme by intracerebral perfusion of interleukin-2 and LAK cells. Eur Cytokine Netw 1993;4:331-341.

121. Jacobs SK, Wilson DJ, Kornblith PL, Grimm EA. Interleukin-2 or autologous lymphokine-activated killer cell treatment of malignant glioma: phase I trial. Cancer Res 1986;46:2101-2104.

122. Jeffes EW, 3rd, Beamer YB, Jacques S, et al. Therapy of recurrent high grade gliomas with surgery, and autologous mitogen activated IL-2 stimulated killer (MAK) lymphocytes: I. Enhancement of MAK lytic activity and cytokine production by PHA and clinical use of PHA. J Neuro-Oncol 1993;15:141-155.

123. Ingram M, Buckwalter JG, Jacques DB, et al. Immunotherapy for recurrent malignant glioma: an interim report on survival. Neurol Res 1990;12:265-273.

124. Quattrocchi KB, Miller CH, Cush S, et al. Pilot study of local autologous tumor infiltrating lymphocytes for the treatment of recurrent malignant gliomas. J Neuro-Oncol 1999;45:141-157.

125. Tsurushima H, Liu SQ, Tuboi K, et al. Reduction of end-stage malignant glioma by injection with autologous cytotoxic $\mathrm{T}$ lymphocytes. Jpn J Cancer Res 1999;90:536-545.

126. Kitahara T, Watanabe O, Yamaura A, et al. Establishment of interleukin 2 dependent cytotoxic $\mathrm{T}$ lymphocyte cell line specific for autologous brain tumor and its intracranial administration for therapy of the tumor. J Neurooncol 1987;4:329-336.

127. Yaghoubi SS, Jensen MC, Satyamurthy N, et al. Noninvasive detection of therapeutic cytolytic T cells with 18F-FHBG PET in a patient with glioma. Nat Clin Pract Oncol 2009;6:53-58. 
128. Dudley ME, Yang JC, Sherry R, et al. Adoptive cell therapy for patients with metastatic melanoma: evaluation of intensive myeloablative chemoradiation preparative regimens. J Clin Oncol 2008.

129. Rosenberg SA, Restifo NP, Yang JC, Morgan RA, Dudley ME. Adoptive cell transfer: a clinical path to effective cancer immunotherapy. Nat Rev Cancer 2008;8:299-308.

130. Muranski P, Boni A, Wrzesinski C, et al. Increased intensity lymphodepletion and adoptive immunotherapy--how far can we go? Nat Clin Pract Oncol 2006;3:668-681.

131. Wrzesinski C, Paulos CM, Gattinoni L, et al. Hematopoietic stem cells promote the expansion and function of adoptively transferred antitumor CD8 T cells. J Clin Invest 2007;117:492-501.

132. Dudley ME, Wunderlich JR, Robbins PF, et al. Cancer regression and autoimmunity in patients after clonal repopulation with antitumor lymphocytes. Science 2002;298:850-854.

133. Tanchot C, Rosado MM, Agenes F, Freitas AA, Rocha B. Lymphocyte homeostasis. Semin Immunol 1997;9:331-337.

134. Grossman Z, Paul WE. Self-tolerance: context dependent tuning of T cell antigen recognition. Semin Immunol 2000;12:197-203.

135. Cho BK, Rao VP, Ge Q, Eisen HN, Chen J. Homeostasis-stimulated proliferation drives naive $\mathrm{T}$ cells to differentiate directly into memory T cells. J Exp Med 2000;192:549-556.

136. Dummer W, Niethammer AG, Baccala R, et al. T cell homeostatic proliferation elicits effective antitumor autoimmunity. J Clin Invest 2002;110:185-192.

137. Asavaroengchai W, Kotera Y, Mule JJ. Tumor lysate-pulsed dendritic cells can elicit an effective antitumor immune response during early lymphoid recovery. Proc Natl Acad Sci U S A 2002;99:931-936.

138. Rapoport AP, Stadtmauer EA, Aqui N, et al. Restoration of immunity in lymphopenic individuals with cancer by vaccination and adoptive T-cell transfer. Nat Med 2005;11:1230-1237.

139. Hu HM, Poehlein CH, Urba WJ, Fox BA. Development of antitumor immune responses in reconstituted lymphopenic hosts. Cancer Res 2002;62:3914-3919.

140. Khoruts A, Fraser JM, Khoruts A, Fraser JM. A causal link between lymphopenia and autoimmunity. Immunol Lett 2005;98:23-31.

141. Krupica T, Jr., Fry TJ, Mackall CL, Krupica T, Jr., Fry TJ, Mackall CL. Autoimmunity during lymphopenia: a two-hit model. Clin Immunol 2006;120:121-128.

142. Lizee G, Radvanyi LG, Overwijk WW, Hwu P. Immunosuppression in melanoma immunotherapy: potential opportunities for intervention. Clin Cancer Res 2006;12:2359s-2365s.

143. Klebanoff CA, Khong HT, Antony PA, Palmer DC, Restifo NP. Sinks, suppressors and antigen presenters: how lymphodepletion enhances T cell-mediated tumor immunotherapy. Trends Immunol 2005;26:111-117.

144. Dudley ME, Wunderlich JR, Yang JC, Sherry RM, Topalian SL, Restifo NP, et al. Adoptive cell transfer therapy following nonmyeloablative but lymphodepleting chemotherapy for the treatment of patients with refractory metastatic melanoma. J Clin Oncol 2005;23:2346-2357.

145. Robbins PF, Dudley ME, Wunderlich J, et al. Cutting edge: persistence of transferred lymphocyte clonotypes correlates with cancer regression in patients receiving cell transfer therapy. J Immunol 2004;173:7125-7130.

146. Rosenberg SA. Development of effective immunotherapy for the treatment of patients with cancer. Journal of the Am Coll Surg 2004;198:685-696.

147. Rosenberg SA, Rosenberg SA. Cancer immunotherapy comes of age. Nat Clin Pract Oncol 2005;2:115.

148. Zhou J, Dudley ME, Rosenberg SA, Robbins PF. Persistence of multiple tumor-specific T-cell clones is associated with complete tumor regression in a melanoma patient receiving adoptive cell transfer therapy. J Immunother Emphasis Tumor Immunol 2005; 28:53-62.

149. Zhou J, Shen X, Huang J, Hodes RJ, Rosenberg SA, Robbins PF. Telomere length of transferred lymphocytes correlates with in vivo persistence and tumor regression in melanoma patients receiving cell transfer therapy. J Immunol 2005;175:7046-7052.

150. Dudley ME, Rosenberg SA. Adoptive-cell-transfer therapy for the treatment of patients with cancer. Nat Rev Cancer 2003;3: $666-675$.
151. Restifo NP, Rosenberg SA, Restifo NP, Rosenberg SA. Use of standard criteria for assessment of cancer vaccines. Lancet Oncol 2005;6:3-4.

152. Wrzesinski C, Paulos CM, Gattinoni L, et al. Hematopoietic stem cells promote the expansion and function of adoptively transferred antitumor CD8 T cells. J Clin Invest 2007;117:492-501.

153. Fecci PE, Mitchell DA, Whitesides JF, et al. Increased regulatory T-cell fraction amidst a diminished CD4 compartment explains cellular immune defects in patients with malignant glioma. Cancer Res 2006;66:3294-3302.

154. Sakaguchi S, Sakaguchi N, Asano M, Itoh M, Toda M. Immunologic self-tolerance maintained by activated $\mathrm{T}$ cells expressing IL-2 receptor alpha-chains (CD25). Breakdown of a single mechanism of self-tolerance causes various autoimmune diseases. J Immunol 1995; 155:1151-1164.

155. Thornton AM, Shevach EM. CD4+CD25+ immunoregulatory T cells suppress polyclonal $\mathrm{T}$ cell activation in vitro by inhibiting interleukin 2 production. J Exp Med 1998;188:287-296.

156. Jonuleit H, Schmitt E, Stassen M, Tuettenberg A, Knop J, Enk $\mathrm{AH}$. Identification and functional characterization of human $\mathrm{CD} 4(+) \mathrm{CD} 25(+) \mathrm{T}$ cells with regulatory properties isolated from peripheral blood. J Exp Med 2001;193:1285-1294.

157. Dieckmann D, Plottner H, Berchtold S, Berger T, Schuler G. Ex vivo isolation and characterization of $\mathrm{CD} 4(+) \mathrm{CD} 25(+) \mathrm{T}$ cells with regulatory properties from human blood. J Exp Med 2001; 193:1303-1310.

158. Fontenot JD, Gavin MA, Rudensky AY. Foxp3 programs the development and function of $\mathrm{CD} 4+\mathrm{CD} 25+$ regulatory $\mathrm{T}$ cells Nat Immunol 2003;4:330-336.

159. Khattri R, Cox T, Yasayko SA, Ramsdell F. An essential role for Scurfin in CD4+CD25+ T regulatory cells. Nat Immunol 2003; $4: 337-342$.

160. Green DR, Webb DR. Saying the "S" word in public. Immunol Today 1993; 14:523-525.

161. Asano M, Toda M, Sakaguchi N, Sakaguchi S. Autoimmune disease as a consequence of developmental abnormality of a $\mathrm{T}$ cell subpopulation. J Exp Med 1996;184:387-396.

162. Salomon B, Lenschow DJ, Rhee L, et al. B7/CD28 costimulation is essential for the homeostasis of the CD4+CD25+ immunoregulatory $\mathrm{T}$ cells that control autoimmune diabetes. Immunity 2000; 12:431-440.

163. Stephens LA, Mason D. CD25 is a marker for CD4+ thymocytes that prevent autoimmune diabetes in rats, but peripheral $\mathrm{T}$ cells with this function are found in both CD25+ and CD25- subpopulations. J Immunol 2000;165:3105-3110.

164. Taguchi O, Nishizuka Y. Self tolerance and localized autoimmunity. Mouse models of autoimmune disease that suggest tissuespecific suppressor $\mathrm{T}$ cells are involved in self tolerance. J Exp Med 1987;165:146-156

165. Taguchi O, Kontani K, Ikeda H, Kezuka T, Takeuchi M, Takahashi T. Tissue-specific suppressor T cells involved in self-tolerance are activated extrathymically by self-antigens. Immunology 1994;82:365-369.

166. Seddon B, Mason D. Regulatory T cells in the control of autoimmunity: the essential role of transforming growth factor beta and interleukin 4 in the prevention of autoimmune thyroiditis in rats by peripheral $\mathrm{CD} 4(+) \mathrm{CD} 45 \mathrm{RC}$-cells and $\mathrm{CD} 4(+) \mathrm{CD} 8(-)$ thymocytes. J Exp Med 1999;189:279-288.

167. Seddon B, Mason D. Peripheral autoantigen induces regulatory T cells that prevent autoimmunity. J Exp Med 1999;189:877-882.

168. Bagavant H, Thompson C, Ohno K, Setiady Y, Tung KSK. Differential effect of neonatal thymectomy on systemic and organspecific autoimmune disease. Intl Immunol 2002;14:1397-1406.

169. Somasundaram R, Jacob L, Swoboda R, et al. Inhibition of cytolytic T lymphocyte proliferation by autologous CD4+/CD25+ regulatory $\mathrm{T}$ cells in a colorectal carcinoma patient is mediated by transforming growth factor-beta. Cancer Res 2002;62:5267-5272.

170. Curiel TJ, Coukos G, Zou L, et al. Specific recruitment of regulatory $\mathrm{T}$ cells in ovarian carcinoma fosters immune privilege and predicts reduced survival. Nat Med 2004;10:942-949.

171. Liyanage UK, Moore TT, Joo HG, et al. Prevalence of regulatory $\mathrm{T}$ cells is increased in peripheral blood and tumor microenviron- 
ment of patients with pancreas or breast adenocarcinoma. J Immunol 2002;169:2756-2761.

172. Wolf AM, Wolf D, Steurer M, Gastl G, Gunsilius E, GrubeckLoebenstein B. Increase of regulatory T cells in the peripheral blood of cancer patients. Clin Cancer Res 2003;9:606-612.

173. Ichihara F, Kono K, Takahashi A, Kawaida H, Sugai H, Fujii H. Increased populations of regulatory $\mathrm{T}$ cells in peripheral blood and tumor-infiltrating lymphocytes in patients with gastric and esophageal cancers. Clin Cancer Res 2003;9:4404-4408.

174. Woo EY, Chu CS, Goletz TJ, et al. Regulatory CD4(+)CD25(+) $\mathrm{T}$ cells in tumors from patients with early-stage non-small cell lung cancer and late-stage ovarian cancer. Cancer Res 2001;61: 4766-4772.

175. Heimberger AB, Abou-Ghazal M, Reina-Ortiz C, et al. Incidence and prognostic impact of FoxP3 + regulatory $\mathrm{T}$ cells in human gliomas. Clin Cancer Res 2008;14:5166-5172.

176. Chen A, Liu S, Park D, Kang Y, Zheng G. Depleting intratumoral $\mathrm{CD} 4+\mathrm{CD} 25+$ regulatory $\mathrm{T}$ cells via FasL protein transfer enhances the therapeutic efficacy of adoptive $\mathrm{T}$ cell transfer. Cancer Res 2007;67:1291-1298.
177. Quezada SA, Peggs KS, Simpson TR, Shen Y, Littman DR, Allison JP. Limited tumor infiltration by activated T effector cells restricts the therapeutic activity of regulatory $\mathrm{T}$ cell depletion against established melanoma. J Exp Med 2008;205:2125-2138.

178. Yu P, Lee Y, Liu W, Krausz T, Chong A, Schreiber H, et al. Intratumor depletion of CD4+ cells unmasks tumor immunogenicity leading to the rejection of late-stage tumors. J Exp Med 2005;201:779-791.

179. Kong L-Y, Abou-Ghazal MK, Wei J, et al. A novel inhibitor of signal transducers and activators of transcription 3 activation is efficacious against established central nervous system melanoma and inhibits regulatory T cells. Clin Cancer Res \% $10.1158 /$ 1078-0432.CCR-08-0377 2008;14:5759-5768.

180. Fecci PE, Sweeney AE, Grossi PM, et al. Systemic anti-CD25 monoclonal antibody administration safely enhances immunity in murine glioma without eliminating regulatory $\mathrm{T}$ cells. Clin Cancer Res 2006;12:4294-4305.

181. Morse MA, Hobeika AC, Osada T, et al. Depletion of human regulatory $\mathrm{T}$ cells specifically enhances antigen-specific immune responses to cancer vaccines. Blood 2008;112:610-618. 